\title{
A rare presentation of diabetic ketoacidosis: Meningeal syndrome
}

\author{
Neslihan Kayahan Satış ${ }^{1}$, İskender Arda Nacar ${ }^{1,2}$, Bilgin Bahadır Başgöz ${ }^{1,2}$, Kenan Sağlam ${ }^{1,2}$, İlker Taşçı ${ }^{1,2}$ \\ (1) Turkish Ministry of Health, Gülhane Training and Research Hospital, Department of Internal Medicine, Ankara, \\ Turkey \\ (2) University of Health Sciences, Gülhane Faculty of Medicine, Department of Internal Medicine, Ankara, Turkey
}

Date submitted:

May 09, 2019

Date accepted:

Jul 22, 2019

Online publication date:

September 15, 2019

\section{Corresponding Author: \\ Bilgin Bahadır Başgöz \\ Turkish Ministry of Health, \\ Gülhane Training and Research \\ Hospital, Department of Internal \\ Medicine, Ankara, Turkey \\ bbbasgoz@gmail.com}

\section{Keywords: Diabetic Ketoacidosis, \\ Meningism, Aseptic Meningitis, \\ Brain edema, Diabetic Ketoacidosis.}

\section{ABSTRACT}

Diabetic ketoacidosis (DKA) typically presents with abdominal pain, vomiting, fatigue, and excessive thirst. Although it is a state of acidosis, symptoms related to the central nervous system are not frequent in DKA. We here report our experience of a patient with DKA receiving immunosuppressive drugs due to renal transplantation who initially presented with the meningeal syndrome. The condition resolved quickly after correction of acidosis and hyperglycemia. In this particular case, we had clues for drug-related side effects of immunosuppressants that possibly facilitated the occurrence of meningeal irritation. Our observations may contribute to the care of patients with DKA who are on such treatment regimens.

\section{Introduction}

Diabetic ketoacidosis (DKA) is a serious complication of diabetes mellitus (DM) and can be the initial presentation of the disease in some patients. On the other hand, most patients with DKA typically present with abdominal pain, vomiting, fatigue, and excessive thirst.

The Meningeal syndrome is another problematic condition in the emergency room, characterized by the symptoms and findings of altered state of consciousness, headache, fever, dizziness, and neck rigidity. Infections and malignancies are the most common causes of the meningeal syndrome, while other less frequent factors such as heat stroke, autoimmune diseases, adverse drug reactions or post-vaccination may also be encountered (1-4).

Although changes in blood gasses are the hallmark of DKA, many patients do not have central nervous system depression due to acidemia. Further, meningeal irritation associated with acidosis, hyperglycemia or increased osmolarity is unlikely. We here report a sporadic patient with DKA who presented with the signs of meningeal irritation which improved after successful treatment.

\section{Case Presentation}

A 40-year-old woman with known type 1 DM, hypertension and functional renal transplantation due to diabetic nephropathy for 3 years was admitted to the emergency room with an altered state of consciousness, disorientation, and agitation. Her medications included insulin aspart 14 Units/day (total daily dose), insulin detemir 24 Units/day, mycophenolate mofetil $1080 \mathrm{mg} / \mathrm{day}$, everolimus $1 \mathrm{mg} /$ day, methylprednisolone $4 \mathrm{mg} /$ day, sodium bicarbonate $2 \mathrm{~g} / \mathrm{day}$, nebivolol $2.5 \mathrm{mg} /$ day, doxazosin $4 \mathrm{mg} /$ day, diltiazem $240 \mathrm{mg} /$ day and nitrofurantoin $100 \mathrm{mg} /$ day. However, her medical history obtained from relatives revealed that she has not been using insulin therapy recently. Her vitals were as follows: blood pressure $125 / 80 \mathrm{mmHg}$, heart rate 97 beats per minute, body temperature $37.2^{\circ} \mathrm{C}$, and respiratory rate 24 per minute. Physical examination revealed Kussmaul breathing pattern, meningeal irritation signs including neck stiffness and positive for Kernig's and Brudzinski's signs. The blood and urine test results at the time of admission and after treatment were given in Table I. 
Table 1. The blood and urine test results ufon admission and after treatment

\begin{tabular}{lccc}
\hline & $\begin{array}{c}\text { Time of } \\
\text { Admission }\end{array}$ & $\begin{array}{c}\text { After } \\
\text { Treatment }\end{array}$ & $\begin{array}{c}\text { Reference } \\
\text { Range }\end{array}$ \\
\hline White blood cell count (cells/uL) & $20.6 \times 10^{\wedge} 3$ & $15.9 \times 10^{\wedge} 3$ & $4.49-10.910^{\wedge} 3$ \\
\hline Hemoglobin (g/dL) & 15.0 & 12.5 & $11.9-14.6$ \\
\hline Platelets (cells/uL) & $273 \times 10^{\wedge} 3$ & $270 \times 10^{\wedge} 3$ & $171-388 \times 10^{\wedge} 3$ \\
\hline Neutrophil count (cells/uL) & $19.2 \times 0^{\wedge} 3$ & $9.6 \times 10^{\wedge} 3$ & $2.1-8.89 \times 10^{\wedge} 3$ \\
\hline Glucose (mg/dL) & 398 & 117 & $74-110$ \\
\hline Urea (mg/dL) & 57 & 44 & $17-43$ \\
\hline Creatinine (mg/dL) & 1.09 & 1.01 & $0.66-1.09$ \\
\hline Sodyum (mmol/L) & 142 & 144 & $136-146$ \\
\hline Potassium (mmol/L) & 4.5 & 4.68 & $3.5-5.1$ \\
\hline Alanine aminotransferase (ALT) (U/L) & 41 & 38 & $7-35$ \\
\hline Aspartate aminotransferase (AST) (U/L) & 77 & 54 & $15-35$ \\
\hline Gamma-glutamyl transferase (GGT) (U/L) & 13 & 10 & $0-38$ \\
\hline Alkaline phosphatase (ALP) (U/L) & 85 & 62 & $40-120$ \\
\hline Lactate dehydrogenase $(\mathrm{LDH})(\mathrm{U} / \mathrm{L})$ & 398 & 243 & $0-247$ \\
\hline C-reactive protein (CRP) $\mathrm{mg} / \mathrm{L}$ & 107.9 & 18.7 & $0-5$ \\
\hline Erythrocyte sedimentation rate (ESR) $(\mathrm{mm} / \mathrm{h})$ & 24 & 22 & $0-30$ \\
\hline Blood gas pH & 7.24 & 7.41 & $7.35-7.45$ \\
\hline Bicarbonate (mmol/L) & 11.6 & 21.9 & $22-26$ \\
\hline Urine pH & 5.5 & 6.0 & $4.5-8.0$ \\
\hline Urine keton & ++++ & Negative & Negative \\
\hline Urine glucose & ++++ & + & Negative \\
\hline
\end{tabular}

as follows; hemoglobin: $15 \mathrm{~g} / \mathrm{dl}$ (11.9-14.6), white blood cell count: $20.6 \times 10^{3}$ cells $/ \mu \mathrm{L}\left(4.49-10.9 \times 10^{3}\right)$, neutrophil count: $19.2 \times 103 \mathrm{cells} / \mu \mathrm{L}\left(2.1-8.89 \times 10^{3}\right)$, olatelet counr: $273 \times 10^{3}$ cells/ $\mu \mathrm{L}\left(171-388 \times 10^{3}\right)$, glucose: $398 \mathrm{mg} / \mathrm{dL}(74-110)$, creatinine: $1.09 \mathrm{mg} / \mathrm{dL}(0.66-1.09)$, urea: $57 \mathrm{mg} / \mathrm{dL}(17-43)$, sodium:142 mmol/L (136-146), potassium: $4.5 \mathrm{mmol} / \mathrm{L}$ (3.5-5.1), alanine aminotransferase (ALT): $41 \mathrm{U} / \mathrm{L}(7-35)$, aspartate aminotransferase (AST): $77 \mathrm{U} / \mathrm{L}(15-35)$, alkaline phosphatase:85 U/L (40-120), gamma-glutamyl transferase: $13 \mathrm{U} / \mathrm{L}(0-38)$, lactate dehydrogenase: $398 \mathrm{U} / \mathrm{L}(0-247)$, serum albumin: $4.11 \mathrm{~g} /$ $\mathrm{dL}$ (3.5-5.2), erythrocyte sedimentation rate: $24 \mathrm{~mm} / \mathrm{h}(0-30)$, C-reactive protein: $107.9 \mathrm{mg} / \mathrm{L}(0-5)$, blood gas $\mathrm{pH}: 7.24$ (7.357.45), bicarbonate: $11.6 \mathrm{mmol} / \mathrm{L}$. In addition to normal urine $\mathrm{pH}$ and density, the patient had severe glucosuria $(++++)$ and ketonuria $(++++)$. Lumbar puncture was negative for bacterial meningitis. Cranial diffusion magnetic resonance imaging and computerized cranial tomography showed no pathological signs of hemorrhage, ischemia or tumor. The patient was diagnosed with DKA and hospitalized in the intensive care unit. With treatment including hydration, insulin, and potassium replacement blood gases, glucose and other metabolic values returned to normal and the meningeal irritation signs gradually resolved by the 24th hour of hospitalization. The patient was discharged home with full recovery.

\section{Discussion}

Herein we present an interesting DKA patient with typical symptoms of the meningeal syndrome including altered state of consciousness and neck stiffness. We specifically excluded common causes (i.e., infections, tumors) of the syndrome using appropriate tools such as head scans and lumbar puncture.
Moreover, the state of aseptic meningitis relieved after effective treatment of DKA.

Current knowledge and available reports suggest that an atypical presentation of DKA is quite unusual. An interesting initial presentation of an acromegaly patient with DKA due to prolonged hyperglycemia was previously reported (5). However, reports of meningeal irritation associated with DKA are extremely rare (6) Several authors have suggested that cerebral edema associated with DKA may cause meningeal irritation in DKA (7-9). However, cerebral edema is also rare (10) and whether it responds quickly to the correction of acidemia in DKA is not known. Moreover, in contrast to our 40-year old patient, cerebral edema is frequently seen among children (11). Besides, DKA patients with cerebral edema are at increased risk of mortality than those without ( $35 \%$ vs. $1.1 \%$, respectively) (12).

We were not able to identify any report of meningeal irritation related to acidosis in different conditions, hyperglycemia or increased plasma osmolarity in the literature. However, our patient was receiving mycophenolate mofetil and everolimus as immunosuppressive therapy for transplant kidney. Aseptic meningitis, encephalopathy, headache, and seizures were listed among the common the side effects of biological treatments and immunosuppressants $(13,14)$. Therefore, in our patient, acidosis, hyperglycemia or hyperosmolarity might have triggered everolimus induced aseptic meningitis, which rapidly recovered after correction of the metabolic disturbances. Nevertheless, this hypothesis remains to be supported by future observations. 


\section{Conclusions}

Albeit rare among adult patients, a sudden onset of severe neurological symptoms in a patient with DKA requires differential diagnosis of the possible causes of the meningeal syndrome in the absence of apparent etiologic factors. Comorbidities and possibilities of drug-related causes that facilitate the occurrence of meningeal irritation may improve clinical management in rare cases.

Acknowledgments: NKS and IAN evaluated and followed the case. NKS, IAN, and BBB collected data. BBB and IT wrote the manuscript. KS critically reviewed the final version.

Conflict of Interest: The authors declared they do not have anything to disclose regarding conflict of interest with respect to this manuscript.

\section{References}

1. Ni Lochlainn M, Gooi HC, Ogese MO, Naisbitt DJ, Jafar-Mohammadi B. Trimethoprim-induced aseptic meningism. British journal of hospital medicine (London, England : 2005). 2017;78(2):108-109.

2. Carayon A, Martin M, Girard P. [Cerebromeningeal accidents during sunstroke in the tropics. Neurosurgical complications]. Medecine tropicale : revue du Corps de sante colonial. 1962;22:347-354.

3. Bozek M, Konopko M, Wierzba-Bobrowicz T, Witkowski G, Makowicz G, Sienkiewicz-Jarosz H. Autoimmune meningitis and encephalitis in adult-onset still disease - Case report. Neurologia i neurochirurgia polska. 2017;51(5):421-426.

4. Mamishi S, Sarkardeh M, Pourakbari B, Keshavarz Valian S, Sabouni F, Mahmoudi S. Aseptic meningitis after measles-mumps-rubella (MMR) vaccination. British journal of biomedical science. 2016;73(2):84-86.

5. Dosi RV, Patell RD, Shah PJ, Joshi HK. Diabetic ketoacidosis: an unusual presentation of acromegaly. BMJ case reports. 2013;2013.

6. Albareda MM, Wagner A, Puig M, Corcoy R. Is diabetic ketoacidosis a cause of meningeal syndrome? Case report. Diabetes care. 1998;21(9):1572-1573.

7. Warncke K, Dressel P, Ziegler AG, Steinborn M, Bonfig W, Burdach S, et al. Severe pretreatment cerebral edema in newly diagnosed type 1 diabetes. Hormone research in paediatrics. 2014;81(4):285-288.

8. Meaden CW, Kushner BJ, Barnes S. A Rare and Lethal Complication: Cerebral Edema in the Adult Patient with Diabetic Ketoacidosis. Case reports in emergency medicine. 2018;2018:5043752.

9. Hiller KM, Wolf SJ. Cerebral edema in an adult patient with diabetic ketoacidosis. The American journal of emergency medicine. 2005;23(3):399-400.

10. Edge JA, Hawkins MM, Winter DL, Dunger DB. The risk and outcome of cerebral oedema developing during diabetic ketoacidosis. Archives of disease in childhood. 2001;85(1):16-22.

11. Edge JA, Jakes RW, Roy $Y$, Hawkins M, Winter D, Ford-Adams ME, et al. The UK case-control study of cerebral oedema complicating diabetic ketoacidosis in children. Diabetologia. 2006;49(9):2002-2009.

12. Siwakoti K, Giri S, Kadaria D. Cerebral edema among adults with diabetic ketoacidosis and hyperglycemic hyperosmolar syndrome: Incidence, characteristics, and outcomes. Journal of diabetes. 2017;9(2):208-209.

13. Rabinstein A. Neurocritical Care, An Issue of Neurologic Clinics, Volume 35-4 1st Edition2017.

14. Pizzi M, Ng L. Neurologic Complications of Solid Organ Transplantation. Neurologic clinics. 2017;35(4):809-823. 